\title{
Manpower imbalance in obstetrics and gynaecology
}

\author{
J G HILL, R W TAYLOR, H K BASU
}

The present imbalance between the number of middle grade posts (registrars and senior house officers) and the career opportunities in the hospital service is clear to all. It has, however, proved hard to reconcile the conflicting interests of patients, consultants, junior hospital staff, and government paymasters. Some of the more radical solutions that have been put forward, such as increasing the number of consultants and financing this by reducing junior staff, may be possible in some of the more contemplative specialties such as general medicine, pathology, radiology, etc, but in obstetrics and gynaecology this solution is totally inappropriate. This is largely because of the need to provide skilled resident medical cover; the modern labour ward is an intensive care unit.

The chronic shortage of money for the maternity services over many years has resulted in many obstetricians working in small divided units, housed in inappropriate and out of date buildings.

Patients understandably want a greater proportion of their care provided by fully trained medical staff, rather than by juniors in training. A close working relationship between consultant and labour wards is necessary if perinatal services are to be improved. Given that 24 hour cover is required, there must be an increase in consultant numbers if increased consultant care is to be achieved, and this would go some way to relieve the present overprovision of doctors in the training grades. Changes of this nature have serious implications for training programmes and may change the nature of the consultant post, bringing consultants' working practices closer to those of their American or western European counterparts. This would be expensive and not necessarily in the best interests of the patients or the Health Service.

In the belief that the present service has many good qualities that should not be needlessly jeopardised by sudden or too radical change the obstetric and gynaecological specialist subcommittee of the South East Thames Regional Health Authority asked us to visit each district in the region to look at the workload, including any geographical and structural problems. We were also asked to examine staffing levels and to see how changes could be effected that would eventually satisfy the patients' request for a higher level of direct consultant care and provide better training and a properly balanced career structure, without destroying what is best in the present service. We were looking particularly for practical steps that could be taken without heavy financial commitments.

Department of Obstetrics and Gynaecology, Pembury Hospital, Pembury, Kent

J G HILL, FRCS, FRCOG, consultant

Department of Obstetrics and Gynaecology, St Thomas's Hospital, London SE1 7EH

R W TAYLOR, MD, FRCOG, professor

Department of Obstetrics and Gynaecology, West Hill Hospital, Dartford, Kent

H K BASU, FRCS, MRCOG, consultant

Correspondence to: $\mathrm{Mr} \mathrm{J} \mathrm{G}$ Hill.
The South East Thames Regional Health Authority is divided into 16 districts, including three teaching hospitals, servicing a population of three and a half million. We obtained our information at meetings with consultant representatives in each district.

\section{Workload}

The second report of the House of Commons social services committee on perinatal and neonatal mortality ${ }^{1}$ recommended that each consultant should be responsible for about 500 deliveries each year. At present the mean for England and Wales is 867 (J Malvern, personal communication)-with a range of 605 to 1147 over the 14 English National Health Service regions. In the South East Thames Regional Health Authority the mean is 844 - with a range of 633 to 1166 . There are two units with more than 1000 deliveries per consultant.

This excessive workload has to be considered against a background of the need for improving existing maternity services, the shortcomings of which included the following:

- About half the units in the South East Thames Regional Health Authority are depressing, appalling units in dingy surroundings.

Overcrowded outpatient departments, pressure on beds and theatre time, difficulty in maintaining turnover and controlling waiting lists-circumstances that often lead to crisis conditions.

Split units (sometimes 20 miles apart) with divided responsibility cause extra stress and anxiety about adequacy of junior cover.

If these shortcomings are to be remedied extra money is needed and this is a high priority.

Proper obstetric care requires 24 hour coverage by staff at a uniformly intensive level. Isolated attempts to restrict the working hours of obstetric units by induction and acceleration of labour have been opposed, both by the public and by the profession.

The average gynaecological workload for England and Wales is probably around four major and 10 minor operations a week. The mean number of major operations in the South East Thames Regional Health Authority is three and a half by each consultant a week-ranging from three in one district where there are serious limitations on operating theatre space to five in another district where there is a relatively elderly population. Medical gynaecology is an important part of the gynaecologist's workload but is not easy to assess as it is usually performed on an outpatient basis. Gynaecologists with special skills-subspecialists-also have an added workload because patients with special problems demanding more than the average amount of time and attention are referred to them.

The amount of emergency gynaecology varies throughout the region and depends on the age and social structure of the population. In many units the clinic and theatre workload in 
gynaecology approaches that of general surgery, and this in addition to the more arduous obstetric commitment.

These considerations, especially when taken in conjunction with geographical separation of units in so many districts, support our impressions on going around the region that the consultants in the specialty bear a heavy workload.

\section{Staffing}

The present ratio of consultants to junior staff in the hospital service is $1: 1 \cdot 8$. The declared aim of the Department of Health and Social Security is a $1: 1$ ratio within five years and a reversal of the ratio within 15 years. In obstetrics and gynaecology the ratio for England and Wales is one consultant to $2 \cdot 4$ juniors. In the South East Thames Regional Health Authority the ratio is $1: 2 \cdot 5$. Clearly, the DHSS needs to adjust its views on numbers needed for obstetrics and gynaecology.

\section{EFFECT OF AN INCREASE IN CONSULTANT NUMBERS}

The heavy workload makes a good case for appointing additional consultants -in fact, we identified 10 districts that would welcome a new post.

If the junior staff numbers were to remain the same this would mean a ratio of one consultant to two junior staff, which we consider an acceptable ratio in the unique circumstances of obstetrics.

\section{EFFECT OF REDUCTION OF JUNIOR STAFF}

Junior hospital doctors and consultants have a fundamental difference in responsibilities that is not generally understood by the public. A junior doctor, having spent a night out of bed, does not usually have to make crucial decisions the next day, whereas the consultant does. In any event, the junior does not normally make any ultimate decisions and may (and usually does) ask for help on such occasions. If the consultant was on labour ward duty for 24 hours he would need to be given 24 hours time off. To do this would require a twofold to threefold expansion of the consultant grade.

If the facilities for time off in lieu after labour ward duty were not available for the consultant it is inevitable that, being overtired, he might not have the energy to carry on with his routine work or be able to teach his junior staff or deal with his many administrative functions. In any event, the older consultant is unlikely to sustain the rigours of constant night call.

The quality of intrapartum care has greatly improved in the last decade. If there is a reduction in the middle grade junior staff there will be a lack of an on the spot supervisor of the labour ward, leading to diminished care in the management of prolonged labour, fetal distress, breech delivery, premature labour, etc. All this would result in an altered pattern of obstetric care and possibly an increased number of caesarean sections.

A factor that has been constantly overlooked in the Department of Health's suggestion that junior staff should be reduced is the special need in obstetrics to provide an emergency squad to deal with emergencies outside hospital. This may be even more important in future if the move towards more home confinements gains momentum.

Any reduction in the resident staff of associated specialties such as paediatrics and anaesthetics would also have a serious effect on the present standard of obstetric care. Much of the reduction in recent years of maternal and perinatal mortality is due to advances in these specialties.

Some consultants see a subconsultant grade as solving present manpower problems, and perhaps this idea merits further consideration. This is unlikely, however, to be a long term solution to the problem of covering the delivery unit 24 hours a day. Clinical assistants grow old like consultants and they too find it increasingly difficult to cope with night and day work.

\section{CONSIDERATION OF INDIVIDUAL GRADES}

\section{Senior house officer}

At first sight the number of senior house officers in our specialty seems out of line with other specialties. This is not so. We identified three separate groups of senior house officers who will have to be accommodated in the training structure but who will not practise as career specialists in this country.

(1) Senior house officer posts that are part of vocational training schemes for general practice.

(2) Senior house officer posts used by junior doctors organising their own training for general practice or intending to enter paediatrics, genitourinary medicine, or some other specialty. Both these groups of senior house officers are training for primary care and should more properly be thought of as house officers. They comprise 54 of the 94 senior house officer posts in the region $(57 \%)$.

(3) Senior house officer posts filled by graduates from overseas who are said to be returning home-32 (34\%). The NHS may accept that as a contribution to the developing world it has an obligation to help train specialists from overseas. This is acceptable only if $(a)$ those concerned are intending to return home and $(b)$ they are genuinely being trained and not merely used to provide a service for the NHS. More sponsorship of overseas graduates by their own institutions would help to ensure the first, and a properly organised training programme with participation by the teaching hospitals would help to ensure the second. Time off each week to attend an organised course of training directed especially to part I of the membership examination of the Royal College of Obstetricians and Gynaecologists would be ideal. At present senior house officers are so heavily committed to service work that training in theory and preparation for the part I examination scarcely exists. This problem cannot be solved without spending more money on the obstetric services.

Senior house officers and registrars have too heavy a service workload to permit adequate time for theoretical training, which is a sign that more not fewer junior staff are needed. Pressure from the DHSS to introduce a one in three rota will necessitate an expansion of these grades if the present standard of service is to be maintained. Clearly, the hasty decision to freeze senior house officer posts was ill advised in relation to obstetrics and gynaecology.

\section{Registrar}

At present our region has in training $50 \%$ more registrars than it can accommodate in senior registrar posts, even when we exclude graduates from overseas who say that they intend to return to their own countries. This latter group constitutes half of the registrars in the South East Thames Regional Health Authority. Some will drop out but it is unfair to encourage people to train when there is little future for them in the specialty. Unless a registrar has a teaching hospital post or a post linked to a teaching hospital he stands almost no chance of advancing in this country, and this should be publically acknowledged. If we profess to be training overseas graduates we must (as with United Kingdom trained career registrars) provide time and facilities for theoretical training as well as the practical instruction that they are already receiving. We believe that there is an important place for employing overseas doctors in this grade and that the opportunity to provide suitable short term training appointments for them dovetails neatly with the service requirements for adequate clinical teams. Many consultants in the region enjoy teaching and giving practical training to overseas doctors and derive great satisfaction from watching their subsequent progress and attainment of consultant posts in their own countries.

\section{Senior registrar}

In the South East Thames Regional Health Authority the balance between senior registrar posts and consultants available is about correct at present. Study of the age distribution of consultants, however, suggests that in the absence of new posts there will be a serious shortage of consultant vacancies. A further factor, which may distort the picture, is that between $25 \%$ and $30 \%$ of consultant posts are not filled by senior registrars but by obstetricians from academic departments. The present length of training for senior registrars in obstetrics and gynaecology is about 3.7 years, and we doubt whether this could be reduced appreciably and still produce consultants trained to the standard that patients expect. Changed working patterns and the specialty's increased complexity contrive to make longer rather than shorter training desirable, although in practice longer training would probably be unacceptable to candidates. Even so, subspecialisation is increasing and experience in gynaecological endocrinology, oncology, and fetal medicine can be satisfactorily gained only at senior registrar level. 


\section{Consultants}

By any calculation most districts in the region have too few consultants, a position not widely recognised by consultants in post. Consultants fear that the nature and pattern of their work will change if their numbers increase. We found universal hostility to the idea of consultants returning to carrying out the more mundane work usually performed by senior house officers, and, in particular, none was prepared to return to the position of being resident on call. A substantial number of consultants also opposed carrying out the work now done by registrars, and, in practice, the employment of consultants for such work could be seen as a waste of an expensive training. As we expected most consultants thought that they could cope with any appreciable night work only if they had time off in lieu, and this would seem to be financially out of the question. Interestingly, in one district where three consultants work with three senior house officers (but no registrar) to deliver 1900 patients and carry out a moderately heavy gynaecological workload it has not proved possible to organise a timetable that always allows a free day to follow 24 hours on labour ward duty. The difficulties in accommodating clinics and theatre times with others who use the hospital have made this impossible.

\section{Suggested career structure}

We believe that with some adjustments the concept of a consultant led team to care for patients in obstetrics and gynaecology is correct. The adjustments would mean sessional time being allowed to give consultants more direct participation in the labour wards and the supervision of junior staff. This time must be set aside and be free from all other commitments.

One of the aims of the Short report on medical education ${ }^{2}$ was to improve the career structure, and although the prospects

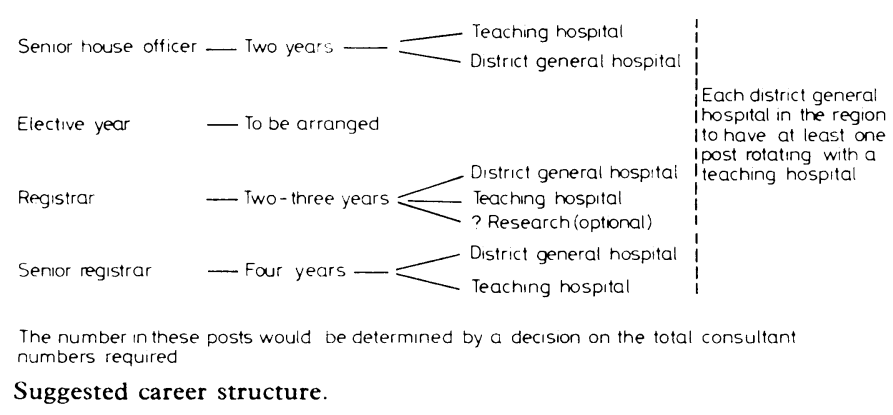

for advancing in obstetrics are satisfactory at present because of poor recruitment in recent years, we recognise the need for a balanced career structure. As a theoretical exercise we have, therefore, tried to view the South East Thames Regional Health Authority as an area completely independent from the rest of the country and to propose a career structure to fill the consultant posts in this particular region (figure).

\section{SENIOR REGISTRARS}

Given that the average working life of a consultant is about 30 years, each senior registrar post services about seven consultant posts. So we need about eight senior registrar posts for 57 consultant posts. The surplus three posts would permit an expansion of the consultant grade of one every two years if we continue to expect senior registrars to serve four years at that level.

\section{REGISTRARS}

To fill the senior registrar posts about 10 career registrars are required. We believe that they should all rotate between teaching hospitals and district general hospitals. If the 10 posts are all rotating this would mean five posts in the district general hospitals linked to the three teaching hospitals.

If this number of career posts is not to be exceeded teaching units must be asked not to accept an unlimited number of research workers in the registrar grade. In most instances the clinical research might well be carried out by doctors fulfilling their elective year before the membership examination of the Royal College of Obstetricians and Gynaecologists, registrars in a planned third year, or clinical assistants not destined for a career in obstetrics and gynaecology.

\section{SENIOR HOUSE OFFICERS}

If it is advantageous for registrars to rotate why not also the senior house officer? We believe that this would be beneficial. The region could take perhaps eight rotating posts (a total of 16 senior house officers) to fill 10 registrar posts, thus allowing for some wastage and migration into associated specialties.

The problem of where they should be allocated would depend on the facilities in the unit, the training available, and opportunities for clinical projects.

It would be advantageous for every district in the region to have, if possible, at least one post rotating with a teaching hospital, whether it be senior registrar, registrar, or senior house officer. This would be encouraging for the district hospital staff, and because of their participation in the structured programme it would be hoped that they would work hard to make the post a successful one. Such a system would virtually provide two stages in the career structure in obstetrics and gynaecology in the South East Thames Regional Health Authority.

(1) A two year rotating senior house officer appointmentfirst year in a teaching hospital, second year in a district general hospital.

(2) Rotating registrar post-also starting with one year in the district and then one or possibly two years in a teaching hospital (two years would permit greater participation in research project).

Such a scheme should encourage the young senior house officer interested in a career in obstetrics and gynaecology. By committing himself to a two year combined senior house officer position he would have the opportunity of much more varied clinical experience without necessarily committing himself irrevocably to a career in obstetrics and gynaecology. This should have more appeal than the present system whereby the senior house officer is fearful of leaving his teaching hospital and at the end of the year has insufficient clinical experience to proceed to a rotating registrar appointment, which almost invariably starts in a busy district general hospital.

We would hope that such a career structure contained within our own region would attract candidates who are perhaps discouraged by the present uncertain career prospects.

\section{OVERSEAS JUNIOR POSTS}

It is not sufficient merely to provide a satisfactory training programme for the senior house officer or registrar aiming at a consultant post in the United Kingdom. If we are to continue to attract the number and quality of overseas doctors at the registrar level that are required to maintain present standards of care it is vital to pay more attention to the training aspect of the posts, which must not be allowed to degenerate into (or remain) just service posts. A properly organised training programme allowing time off each week to attend an organised course of training directed especially at part I of the membership examination would be ideal.

We emphasise that a strong case be made for these posts remaining in the registrar grade (not the senior house officer 
grade, as suggested by the Central Committee for Hospital Medical Services' document ${ }^{3}$ ) as it is the attraction of a registrar appointment that draws the quality candidates from overseas.

Overseas sponsorship must be considered and, if at all possible, implemented either through the Royal College of Obstetricians and Gynaecologists or through the General Medical Council. This would be the ideal way of ensuring that candidates for training from overseas who proved unsatisfactory did not remain unduly long in service posts that would have no ultimate benefit for them.

\section{Conclusions}

\section{WORKLOAD}

The obstetric services in the region are seriously underfunded. Extra money is required to maintain the present high standard of care.

The workload in each district should not merely be equated to the number of deliveries-the surgical and medical gynaecological workload should be assessed along with the demands of subspecialisation.

\section{STAFFING}

Consultants and senior registrars-It is not practicable to have a rapid increase in consultant numbers if the same high standard of training is to be maintained. The region could create and fill one to two extra posts each year. This would be in line with recommendations of the Royal College of Obstetricians and Gynaecologists (J Malvern, personal communication).

Registrars-Obstetrics requires 24 hour coverage by medical staff at a uniformly intensive level and it is vital for the satisfactory functioning of any busy labour ward to maintain the post of registrar. Obstetrics and gynaecology cannot be equated with most other specialties: it is a special case.

It is important to identify those registrar posts which direct an individual towards a career in this country and those that point to a career abroad. At present only 12 out of 24 registrar posts in the region carry a reasonable chance of their occupant obtaining a senior registrar post-a post that will provide a link with a teaching hospital.
Some overseas graduates are not given a balanced training but this could be corrected by an organised training programme with the participation of the teaching hospitals. Some overseas doctors do come to this country requiring only practical training, $\varrho$ and this is usually first class-as may be judged by the high $\subsetneq$ proportion of those who return home to become consultants in $\cong$ their own country. Some registrars, however, do not return home and after four or more years in the grade end up frustrated $\mathbb{D}$ with their careers blocked.

Senior house officers-The number of senior house officer posts $\stackrel{\text { ? }}{2}$ in the region is inadequate for three reasons.

(a) Many senior house officers are overworked and have too little time for theoretical training at the moment-a sign that more junior staff are needed, not fewer.

(b) A senior house officer in training for general practice is not as valuable for service needs as a specialty oriented senior house $\stackrel{\Phi}{\varnothing}$ officer.

(c) With the present number of senior house officers it is impossible to fulfil a one in three rota throughout the region as the DHSS has requested. In some districts there are units with $\overrightarrow{\vec{\omega}}$ only two senior house officers because of separation of depart- $\mathscr{O}$ ments. The workload in some of these units would hardly justify an extra appointment and if an extra senior house officer were to be appointed in order to provide a one in three rota it is $\underset{\infty}{\infty}$ doubtful whether recognition of the post by the Royal College or of Obstetricians and Gynaecologists would be forthcoming. For $\mathcal{E}^{\prime}$ these reasons the establishment of a one in three rota for senior.house officers will be impossible in several districts unless there $\overrightarrow{\vec{v}}$ is some progress towards centralisation.

We thank our colleagues in the South East Thames Regional Health $N$ Authority for their help and advice, and Miss M J Fogg for typing $D$ the paper.

\section{References}

1 House of Commons Social Services Committee. Perinatal and neonatal mortality. Second report. London: HMSO, 1980.

${ }^{2}$ House of Commons Social Services Committee. Medical education. Fourth report. London: HMSO, 1981

3 Anonymous. Medicine, surgery, and obstetrics and gynaecology. CCHMS's proposed career structure. Br Med f 1982;284:1575.

(Accepted 4 February 1983)

\section{Rural dispensing: circular issued}

The Department of Health and Social Security has issued a health notice $(\mathrm{HN}(\mathrm{FP})(83) 9)$ announcing the introduction with effect from 1 April of the control of changes in National Health Service dispensing arrrangements in rural areas recommended in the report of the national joint committee of the medical and pharmaceutical professions on the dispensing of NHS prescriptions in rural areas (the Clothier report).

The NHS (General Medical and Pharmaceutical Services) Amendment Regulations 1983 amend the existing provisions concerning

(a) entry to the "pharmaceutical list" of pharmacists or bodies entitled to lawfully conduct a retail pharmacy business and

(b) the arrangements for NHS dispensing by doctors, which are currently that a doctor may supply drugs and appliances if requested to do so by a patient who either

(i) satisfies the family practitioner committee that he would have serious difficulty in obtaining drugs and appliances from a pharmacist because of distance or inadequate means of communication (the "serious difficulty provision")

or (ii) lives in an area that in the opinion of the family practitioner committee is rural in character at a distance of more than one mile in a straight line from a pharmacy (the "one mile rule")

From 1 April, with certain exceptions, the following will require the consent of the rural dispensing committee-applications by doctors to start or extend NHS dispensing under the "one mile rule" and applications by pharmacists to start NHS dispensing in a rura area.

The General Medical Services Committee, the Pharmaceutical Society of Great Britain, and the Pharmaceutical Services Negotiating Committee have agreed that when these new provisions start on 1 April their "standstill" 을

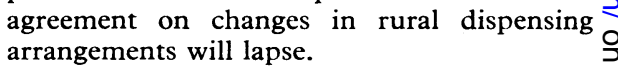

The GMSC's guidelines on the implemen- N tation of the Clothier report were published on 19 March (p 998).

Correction
Rural dispensing: implementation of
Clothier report
In the General Medical Services Committee's
guidelines on the implementation of the Clothier
report ( 19 March, 998 ) the penultimate sentence
hould have read: "As the family practitioner
committee will already have granted the application,
the rural dispensing committee may in these
circumstances only impose conditions-for ex-
ample, specify the method by and the rate at which
patients will be transferred from a doctor's
dispensing to his prescribing list.

